\title{
How to Add a Journal to the International Databases, Science Citation Index Expanded and MEDLINE
}

\section{Sun Huh}

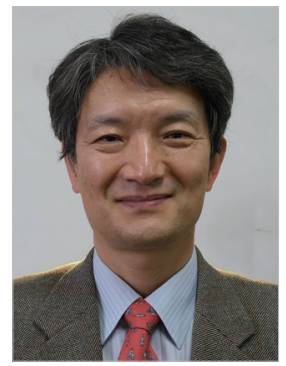

Department of Parasitology and Institute of Medical Education, Hallym University College of Medicine, Chuncheon, Korea

What are the most important international platforms for medical journal literature in the world? They are PubMed, PubMed Central (PMC), MEDLINE, SCOPUS, and Web of Science. Being indexed in all those databases requires meeting vigorous review or selection criteria.

PubMed comprises the more than 26 million citations for biomedical literature at the United States National Library of Medicine up to the present. To be indexed in PubMed, a journal should be selected as a MEDLINE journal or be deposited to PMC, which requires full text JATS XML production. To be included in the Web of Science Core Collection, a journal should be selected for the Science Citation Index Expanded (SCIE) or Emerging Sources Citation Index (ESCI). SCOPUS and Web of Science are best-known reference indexing international databases; therefore, the journal's standing internationally and competitiveness can be determined from its position in these collections. Out of the above five databases, Archives of Plastic Surgery (APS) has already been indexed in PubMed, PubMed Central, and SCOPUS. Furthermore, Thomson Reuters has notified APS that the journal was selected for ESCI in February 2016, although it is not still searchable from the Web of Science Core Collection.

Therefore, I would like to explain the significance of being selected for ESCI and suggest some strategies for the journal to be indexed in SCIE and MEDLINE.

\section{APPLICATION TO SCIENCE CITATION INDEX EXPANDED}

APS has applied twice for SCIE status, but has failed so far. In March 2012, two reasons given for not being accepted were insufficient international diversity among the authors and too few citations from SCIE journals. In February 2016, the same reasons were given again, along with a concern about an excess of non-citable imaging case reports additionally. APS is scheduled to be reevaluated in late 2019. The selection criteria and process have already been announced on the website of Thomson Reuters, available from: http://wokinfo.com/essays/journal-selection-process. Table 1 presents a checklist of the factors I suggest that medical journal editors address to maximize their journal's eligibility for indexing in SCIE. The enumeration in Table 1 is not definitive but arbitrary because Thomson Reuters has not verifying the exact or absolute value of bibliometrics or measurement scale scores needed for acceptance. Therefore, it is only a reference for editors to prepare their journals before application to be evaluated. To be evaluated for the print journal, three sequential issues should be submitted to Thomson Reuters to arrive by the 14th of the next month after publication to the following address:

Thomson Reuters

ATTN: Publication Processing 
Table 1. Checklist for editors of local society journals who apply for their journals to be listed in SCIE

\begin{tabular}{|c|c|c|c|}
\hline No. & Item & Yes & No \\
\hline 1 & $\begin{array}{l}\text { The journal has been published regularly for at least for } 3 \text { issues. Online-only journals have been publishing continuously for at } \\
\text { least } 9 \text { months with at least one article a month, and at least } 20 \text { articles per year. }\end{array}$ & & \\
\hline 2 & The journal is published in English at an international level of quality. & & \\
\hline 3 & The time from submission to publication is less than 1 year. & & \\
\hline 4 & The journal meets research and publication ethics standards. & & \\
\hline 5 & The references are formatted exactly as stipulated in the instructions to authors. & & \\
\hline 6 & The proportion of research articles supported by research funds is at least $10 \%$. & & \\
\hline 7 & The proportion of articles written by editorial board members as corresponding authors is less than $40 \%$. & & \\
\hline 8 & The aims and scope is unique and different from other SCIE journals. It is also described precisely in more than 300 words. & & \\
\hline 9 & The editorial board members and consultants are from at least 15 countries. & & \\
\hline 10 & The number of authors' countries is at least 10 from the most recent year's worth of issues. & & \\
\hline 11 & The journal's manually counted two-year impact factor is greater than $20 \%$ of the JCR ranking of the same category. & & \\
\hline 12 & The manually counted total citation number is greater than the number of citable articles in a year. & & \\
\hline 13 & The aims and scope, editorial board, archives, instructions to authors, and contact info are available on the journal's website. & & \\
\hline 14 & A DOI is provided for each article. . $^{\text {a }}$ & & \\
\hline \multirow[t]{2}{*}{15} & The journal is an open access journal.a) & & \\
\hline & Total & & \\
\hline \multicolumn{4}{|c|}{$\begin{array}{l}\text { The items in this list are suggestions to be used as a reference. } \\
\text { SCIE, Science Citation Index Expanded; JCR, Journal Citation Reports; DOI, digital object identifier. } \\
\text { alttems } 14 \text { and } 15 \text { are included because Web of Science provides the DOI of each article and open access is essential for the maintenance of citation frequency of local } \\
\text { society journal, although these two items have not been mentioned by Thomson Reuters. }\end{array}$} \\
\hline
\end{tabular}

1500 Spring Garden Street

Fourth Floor

Philadelphia, PA 19130 USA

If submitted as an online journal, it is possible to apply by filling out the submission form at the following website: http://ip-science.thomsonreuters.com/info/journalsubmission-front/?utm source $=$ false \&utm_medium $=$ false\&utm_campaign $=$ false.

What seem to be the most common responses from Thomson Reuters when a journal has not been accepted? From my observation, 4 items are common responses: the journal's aims and scope is already well covered by present SCIE journals; the nationality of the authors and editors is not diverse enough; and citation frequency is not sufficient. These factors are difficult for local journals to overcome in a short period. To recruit editorial board members and manuscripts from a variety of countries, the journal leadership must build an international network of editors and leading scholars. To accelerate this network building, co-publishing with the scholarly societies of other countries is recommended, which makes it manageable to assemble an editorial board and recruit manuscripts from authors affiliated with institutions in more than 10 countries. In addition, a journal run by an academic society in Korea can demonstrate leadership among several participating societies. Many journals run by academic societies from Asia, Africa, and South America are still not included in PubMed Central. Therefore, if a Korean society proposes the co-official publication, most societies in other countries are likely to agree to participate. Cooperation with regional societies is also recommended for the same reason.

How can the citations of the journal be increased? First, the choice of the articles themselves is the most important factor. If any article is high quality, it is very likely to be cited because published articles are exposed via PubMed to researchers all over the world. Inviting high quality review articles from top-notch researchers is another strategy. It is well-known that review articles are more frequently cited than articles of other types. To recruit high quality review articles, an international network of editors is important. Second, multinational research, randomized control studies, cohort studies, and epidemiological studies are known to be cited frequently. Therefore, articles with those study designs should be recommended to be submitted. If a scholarly society can provide a research fund, research with funding on specific topics can be solicited from society members.

The merit of being an SCIE journal is tremendous. It is recognized as higher quality work by the Korean government's funding agencies as well as universities, hospitals, and research institutions. Greater credit is given to authors of SCIE journal articles for funding, promotion, employment, and reappointment. Therefore, the number of submissions to a journal usually increases dramatically if it is indexed in SCIE. 


\section{APPLICATION TO MEDLINE}

It is known to be difficult for medical journals from Korea to achieve indexing in MEDLINE. As of October 2016, 28 titles (9.1\%) are indexed in MEDLINE out of 309 journal titles from Korea referenced in the United States National Center for Biological Information database. A number of journals have applied, but most of them have not been accepted. In 2016, the applications of two journals from Korea were successful: Epidemiology and Health and Journal of Educational Evaluation for Health Professions. In 2015, two journals began to be indexed: Cancer Research and Treatment, and the Korean Journal of Medical Education. The acceptance rate is known to be around $10 \%-$ $20 \%$. The application process is described here: https://www. nlm.nih.gov/pubs/factsheets/jsel.html. To be evaluated by the United States National Library of Medicine Literature Selection Technical Review Committee (LSTRC) as a print journal, the most recent four issues if published at least three times a year; the most recent three issues if published biannually; and the most recent two issues if published annually should be dispatched to the following address:

LSTRC Scientific Review Administrator

National Library of Medicine

Building 38A - Room 4N-419

8600 Rockville Pike

Bethesda, MD USA 20894

To be evaluated as an online journal, the journal should be a PMC journal. One more important component of the application is the quality of the journal's contents, its editorial processes, its importance to users, or its overall production up to 3,800 characters (about 460 words). There is a table used by LSTRC to check the quality of the journal's content, importance to readers, and ethics policies which is available from the editorial of Fluoride [1]. If the average score is 4.0 or more, it is usually accepted. If the average score is 3.75 or more and less than 4.0, it is accepted with the condition of providing PubMed XML files. However, besides these criteria, one of the most important considerations is whether the journal is able to enrich the MEDLINE database or not. Therefore, uniqueness of journal content from pre-existing MEDLINE journals should be stressed during the application process. The merit of being indexed in MEDLINE is that Medical Subject Headings are added to articles for better sensitivity and specificity of literature searches and each article's bibliographic information and abstract is automatically added to SCOPUS as a MEDLINE sourced title [2].

\section{MEANING OF EMERGING SOURCES CITATION INDEX}

From November 2016, Thomson Reuters launched the Emerging Sources Citation Index (ESCI) (http://wokinfo.com/products_tools/multidisciplinary/esci/). Among journals that have applied to SCIE, SSCI, and A\&HCI, those that have not been chosen for indexing in those three databases but are high quality and peer-reviewed publications of regional importance or in emerging scientific fields may be listed in the ESCI. These journals are then searchable from the Web of Science Core Collection; this makes it convenient to trace their performance by metrics such as citations and range of nationalities of authors or editors. These metrics can in turn be used for supporting an application to SCIE, SSCI, or A\&HCI. It can be said that an ESCI journal is a candidate journal to these three other databases. To be ESCI, no special application is required. Just applying to SCIE is enough. Up to October 7, 2016, 46 journals (0.9\%) were from Korea out of 4,891 ESCI-listed journals. Out of these 46 journals, 14 are medical journals. After being added to ESCI, the performance of APS will be traced and considered when it is re-evaluated in late 2019. Therefore, from now to late 2019, we should do all we can to address the three weaknesses of APS noted by the Thomson Reuters editor.

As far as the editor of a local academic societies' journal is concerned, adding the journal to SCIE and MEDLINE to make the journal competitive internationally should be a central concern. After being included in SCIE, the Journal Citation Reports (JCR) ranking is officially announced and other journal metrics are disclosed, and it is easy to identify the journal's position in the journal network. It is not easy to understand the perspective of the editor at Thomson Reuters or members of the LSTRC. Journal editors can only do their best to edit and publish according to the aims and scope of the journal with an international level of quality. I know very well how much the editors of APS have devoted themselves to the success of the journal and how much the Executive Board of the Korean Society of Plastic and Reconstructive Surgeons, the publisher of APS, has supported the journal. Their tireless efforts will lead APS to become a topnotch journal in the field of plastic and reconstructive surgery in the near future as well as an SCIE- and MEDLINE-indexed journal.

\section{ORCID}

Sun Huh http://orcid.org/0000-0002-8559-8640 


\section{REFERENCES}

1. Spittle B. Further MEDLINE rejection of the Fluoride [Internet]. Dunedin: The International Society for Fluoride Research Inc.; c2014 [cited 2016 Oct 30]. Available from: http://www.fluorideresearch.org/471/files/FJ2014_v47_ n1_p002-008_sfs.pdf.

2. Huh S. Promotion to MEDLINE, indexing with Medical Subject Headings, and open data policy for the Journal of Educational Evaluation for Health Professions. J Educ Eval Health Prof 2016;13:14.
Correspondence: Sun Huh

Department of Parasitology and Institute of Medical Education, Hallym University College of Medicine, 1 Hallimdaehak-gil, Chuncheon 24252, Korea

Tel: +82-33-248-2652, Fax: +82-33-241-6765, E-mail: shuh@hallym.ac.kr

No potential conflict of interest relevant to this article was reported.

Received: 23 Oct $2016 \bullet$ Revised: 24 Oct 2016 • Accepted: 25 Oct 2016

pISSN: 2234-6163・ eISSN: 2234-6171

https://doi.org/10.5999/aps.2016.43.6.487 • Arch Plast Surg 2016;43:487-490 